\title{
O Papel dos Stakeholders na Sustentabilidade da Empresa: Contribuições para Construção de um Modelo de Análise
}

\section{Stakeholder Management and Organizational Sustainability: a Brazilian Case Study from the Forestry Sector}

Mariana Galvão Lyra *

Especialista em Gerenciamento de Projetos pela FGV. Professora Substituta da UFES, Vitória/ES, Brasil.

Ricardo Corrêa Gomes Doutor em Administração Pública pela Aston University, Reino Unido. Professor Adjunto III da UFV, Viçosa/MG, Brasil.

Laércio Antônio Gonçalves Jacovine Doutor em Ciências Florestais pela UFV. Professor Adjunto do Departamento de Engenharia Florestal da UFV, Viçosa/MG, Brasil.

* Endereço: Mariana Galvão Lyra

Departamento de Administração - CCJE, Av. Fernando Ferrari, 514, Campus Goiabeiras, Vitória/ES, 29075910. E-mail: mglyra@gmail.com

Copyright (C) 2009 RAC. Todos os direitos, inclusive de tradução, são reservados. É permitido citar parte de artigos sem autorização prévia desde que seja identificada a fonte. 


\title{
RESUMO
}

Este artigo tem como objetivo analisar a Empresa Alfa e seus stakeholders e buscar formas de inferir que uma melhor gestão de stakeholders pode repercutir positivamente no processo de sustentabilidade da empresa. Para isso duas metodologias internacionais previamente testadas serão aplicadas no contexto brasileiro: o diagrama de Venn de Mitchell, Agle e Wood (1997) que contém sete tipos de stakeholders segundo as combinações dos atributos poder, legitimidade e urgência; e a matriz de Savage, Nix, Whitehead e Blair (1991), que analisa a propensão dos stakeholders em colaborar ou ameaçar as estratégias da empresa. Os principais resultados dizem respeito ao desalinho nos discursos dos diversos stakeholders com relação às práticas da empresa e às sugestões de políticas gerenciais para contornar esta situação. Entretanto o estudo se limita a traçar estratégias, sendo necessário, portanto, estudos posteriores com acompanhamentos in loco para analisar a evolução da empresa com a aplicação do estudo. As ferramentas apresentadas podem ser testadas em empresas de diferentes setores que têm preocupações com relacionamento de stakeholders e com os impactos de seus negócios na sociedade.

Palavras-chave: estratégia; responsabilidade social; administração de stakeholders; sustentabilidade.

\begin{abstract}
This article aims to analyze the Alpha Company and its stakeholders, attempting to find ways to contribute to better stakeholder management, bringing positive changes to the corporate sustainability process. To achieve this objective, two previously tested international methodologies are employed in the Brazilian context: Venn's diagram from Mitchell, Agle e Wood (1997), which presents seven stakeholder types according to the combinations of the attributes of power, legitimacy and urgency; and the Savage, Nix, Whitehead e Blair (1991) matrix, a model to identify how to manage the relationship with key-stakeholders by threats or cooperation; The main results are related to the discourse desaligning from the stakeholders concerned with Alpha's practices and suggestions to manage this finding. However, this research is limited on drawing strategies, and ongoing studies are required to analyze the evolution of the company with the application of this study. The tools presented here could be tested within organizations from different sectors considering their concerns with stakeholder management and its environmental and social impacts on the community.
\end{abstract}

Key words: strategy; social corporate responsibility; stakeholder management; sustainability. 


\section{INTRODUÇÃO}

A expansão da consciência coletiva com relação ao meio ambiente e à complexidade das atuais demandas ambientais que a sociedade repassa às organizações induz a um novo posicionamento por parte das organizações em face de tais questões (Tachizawa, 2002).

Nesse sentido, a busca de procedimentos, mecanismos, arranjos e padrões comportamentais desenvolvidos pelas empresas delimita aquelas que são mais ou menos capazes de responder aos anseios da sociedade (Donaire, 1999).

Assim, este estudo se destina a analisar as ações da Empresa Alfa e oferecer alternativas de políticas gerenciais. A empresa foi analisada in loco e entrevistas foram feitas com as partes interessadas, assim como o estudo dos relatórios e documentos disponíveis, para sondar a profundidade, a amplitude e consistência do que vem sendo realizado com relação à sustentabilidade empresarial.

O objetivo do estudo é indicar como o conhecimento de cada stakeholder da Empresa Alfa é capaz de propor melhorias no relacionamento da empresa com esses atores e influenciar positivamente no processo de sustentabilidade empresarial. Sendo assim, a problemática deste estudo busca responder à seguinte questão: Estando a sustentabilidade empresarial fortemente atrelada à demanda crescente de interesse dos stakeholders de uma organização nas práticas desta empresa, como a administração de partes interessadas no negócio da Empresa Alfa pode ser eficiente no processo de sua sustentabilidade empresarial?

\section{REFERENCIAL TEÓRICO}

\section{Responsabilidade Social Corporativa (RSC)}

As empresas contemporâneas precisam atrelar seus objetivos financeiros e econômicos às questões relacionadas com a cidadania, ética nos negócios e preservação do meio ambiente. Aos olhos da sociedade, a conduta socialmente relevante vem sendo percebida como decisiva para definir prognósticos de sucesso ou fracasso empresarial (Costa \& Carvalho, 2005).

A RSC tem como característica abranger várias dimensões do relacionamento ético que uma empresa deve ter com os diversos grupos de interesse da sociedade. Estes grupos de interesse, também conhecidos como stakeholders, representam qualquer público que afeta a empresa ou por ela é afetado em seus objetivos organizacionais (Freeman, 1984, tradução nossa). Essa abordagem nos leva a crer que a legitimidade que os stakeholders vêm assumindo nesta nova concepção de relacionamento é um dos pilares para o entendimento da RSC (Mostardeiro \& Ferreira, 2005).

\section{Stakeholders}

Stakeholder em uma organização é, por definição, qualquer grupo ou indivíduo que pode afetar ou ser afetado pela realização dos objetivos dessa empresa (Freeman, 1984, tradução nossa). Stakeholder inclui aqueles indivíduos, grupos e outras organizações que têm interesse nas ações de uma empresa e que têm habilidade para influenciá-la (Savage, Nix, Whitehead, \& Blair, 1991). Ao negligenciarem esses grupos, algumas empresas já foram devastadas ou destruídas (Tapscott \& Ticoll, 2005).

Os principais objetivos nas pesquisas de stakeholder têm sido identificar quem são os stakeholders da empresa e determinar quais tipos de influência eles exercem (Rowley, 1997, tradução nossa). Dessa forma, Mitchell, Agle e Wood (1997, tradução nossa) assumiram num estudo sobre a teoria de stakeholders que as várias classes de stakeholders devem ser identificadas com base na possessão ou 
na possessão atribuída a um ou à combinação desses atributos: poder, legitimidade e urgência. A partir dessa definição, foram identificados sete tipos de stakeholders, indicando que as entidades que não possuíssem nenhum dos três atributos não seriam consideradas stakeholders e, por isso, não teriam relevância na administração da organização.

A idéia de mapear os stakeholders de acordo com suas influências vem sendo utilizada por estudos empíricos, como o de Bourne e Walker (2005, tradução nossa) que enfatizam o uso de uma ferramenta que auxilia no processo de mapear a visualizar o poder e a influência dos stakeholders que têm impacto primordial no sucesso ou fracasso de um projeto.

Conhecer os gaps entre o que os membros da empresa consideram como essencial, o que a empresa projeta e como os stakeholders externos percebem esses atributos, fornece elementos para que a empresa defina estratégias mais eficazes de posicionamento e relacionamento, construindo imagens mais coerentes e consistentes e uma reputação mais forte (Almeida \& Muniz, 2005).

Para sobreviver, as empresas devem traçar metas para suas relações com stakeholders atuais e em potencial como parte de um processo estratégico contínuo de administração. Essas metas devem considerar o impacto potencial dos stakeholders nas unidades estratégicas corporativas e de negócios. Tendo o potencial dos stakeholders-chave como foco para ameaçar ou cooperar, os executivos podem evitar a implementação de planos que serão opostos aos dos stakeholders, reconhecendo suas necessidades, modificando planos para envolvê-los, e esquivando-se de problemas associados com a organização subjugados pelos stakeholders (Savage et al., 1991, tradução nossa).

\section{O Modelo de Mitchell et al. (1997)}

Mitchell et al. (1997, tradução nossa) sugerem que a interferência dos stakeholders em uma organização se dá por mediação de três atributos: poder, legitimidade e urgência. A combinação desses atributos gera sete tipos diferentes de stakeholders (Figura 1).

\section{Figura 1: Tipos de Stakeholder}

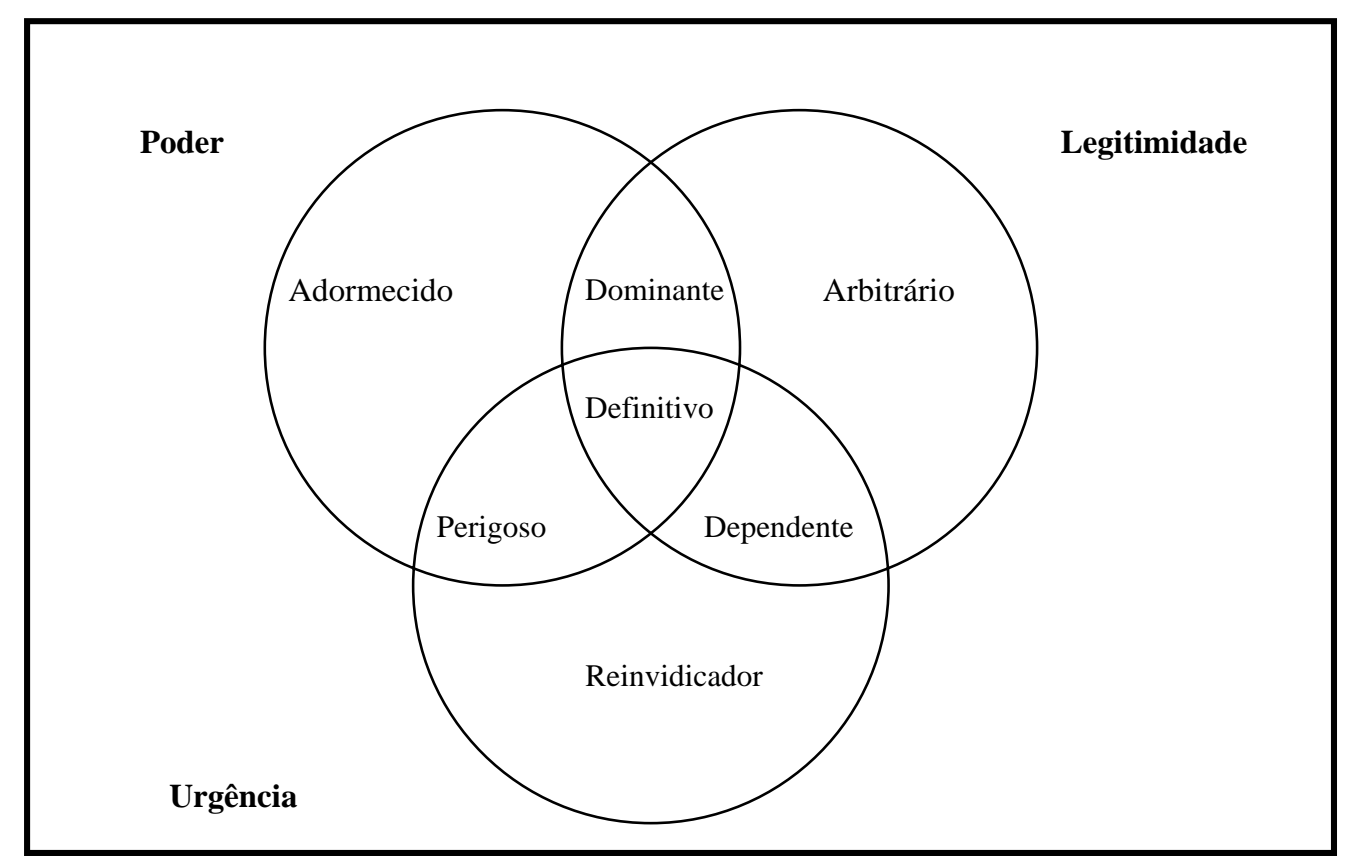

Fonte: Mitchell et al. (1997, p. 874). 
1) Stakeholder Adormecido. Tem poder para impor sua vontade na organização, porém não tem legitimidade ou urgência e, assim, seu poder fica em desuso, tendo pouca ou nenhuma interação com a empresa. A empresa deve conhecer esse stakeholder para monitorar seu potencial em conseguir um segundo atributo.

2) Stakeholder Arbitrário. Possui legitimidade, mas não tem poder de influenciar a empresa nem alega urgência. A atenção que deve ser dada a essa parte interessada diz respeito à responsabilidade social corporativa, pois tende a ser mais receptiva.

3) Stakeholder Reivindicador. Quando o atributo mais importante na administração do stakeholder for urgência, ele é reivindicador. Sem poder e sem legitimidade, não deve atrapalhar tanto a empresa; porém deve ser monitorado quanto ao potencial de obter um segundo atributo.

4) Stakeholder Dominante. Tem sua influência na empresa assegurada pelo poder e pela legitimidade. Espera e recebe muita atenção da empresa.

5) Stakeholder Perigoso. Quando há poder e urgência, porém não existe a legitimidade, o que existe é um stakeholder coercitivo e possivelmente violento para a organização, o que pode ser um perigo, literalmente.

6) Stakeholder Dependente. Tem alegações com urgência e legitimidade, porém depende do poder de um outro stakeholder para ver suas reivindicações sendo levadas em consideração.

7) Stakeholder Definitivo. Quando possui poder e legitimidade, já praticamente se configura como definitivo. Quando, além disso, alega urgência, deve-se dar atenção imediata e priorizada a esse stakeholder.

Para satisfazer os stakeholders-chave, deve-se primeiro identificar aqueles que influenciam a organização. A seguir fazer duas avaliações críticas: o potencial desses stakeholders em ameaçar a organização e o potencial desses stakeholders em cooperar com a organização. Sendo assim, tem-se quatro classes de stakeholders segundo classificação de Savage et al. (1991) (Figura 2):

Figura 2: Diagnóstico dos Tipos de Stakeholders

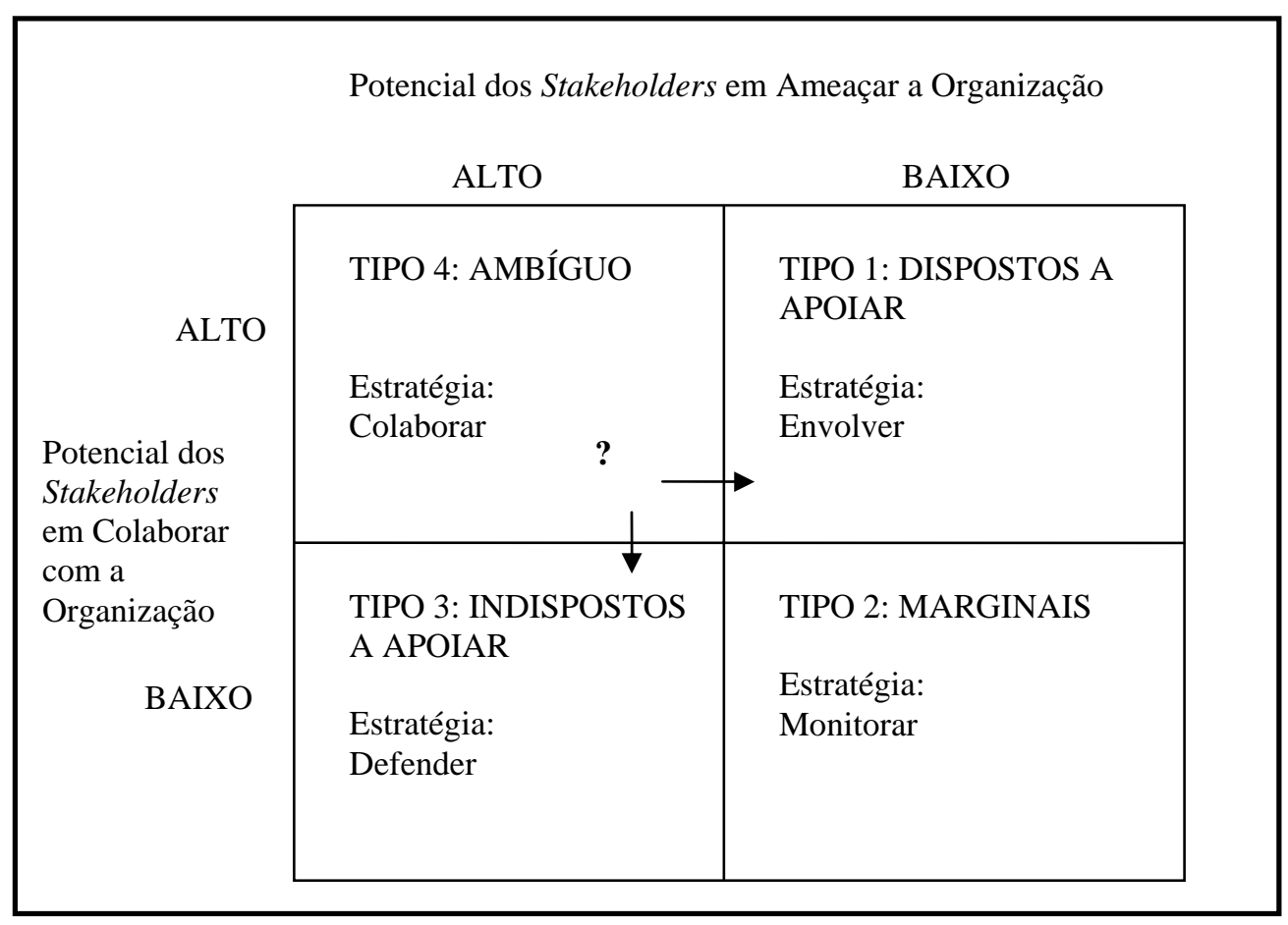

Fonte: Savage et al. (1991, p. 65, tradução nossa). 
1) Stakeholders Dispostos a apoiar - possuem baixo potencial em ameaçar e alto potencial em cooperar.

2) Stakeholders Marginais - não são nem altamente ameaçadores, nem especialmente cooperadores.

3) Stakeholders Indispostos a cooperar - possuem alto potencial de ameaça, mas baixo potencial em cooperação.

4) Stakeholders Ambíguos - têm alto potencial em ameaçar, assim como em cooperar.

O potencial do stakeholder em cooperar, às vezes, é ignorado, porque a análise geralmente enfatiza tipos e magnitudes de ameaças de stakeholders. O potencial para a cooperação do stakeholder é particularmente relevante, porque ele pode levar as companhias a unir forças com outros stakeholders, resultando numa melhor administração dos meios de negócios. Freqüentemente, quanto mais dependente o stakeholder for, maior é a vontade de cooperar (Savage et al., 1991, tradução nossa).

As empresas, ao focar no potencial dos stakeholders-chave para ameaçar e cooperar, podem evitar a implementação de planos opostos aos planos dos stakeholders, reconhecer suas necessidades emergentes, modificar planos para envolvê-los e desviar problemas associados à organização (Savage et al., 1991, tradução nossa).

\section{METODOLOGIA}

A presente pesquisa foi desenvolvida durante 27 meses nos anos de 2004 a 2007, com o apoio financeiro do Conselho Nacional de Desenvolvimento Científico e Tecnológico [CNPq], envolvendo o Departamento de Engenharia Florestal e o Departamento de Administração, ambos pertencentes à Universidade Federal de Viçosa [UFV].

É uma pesquisa eminentemente qualitativa e caracterizada como estudo de caso, por se tratar de investigação empírica que analisa um "fenômeno contemporâneo dentro de seu contexto da vida real, especialmente quando os limites entre o fenômeno e o contexto não estão claramente definidos" (Yin, 1994, p. 32).

A grande dificuldade da equipe foi encontrar uma empresa que autorizasse a realização in loco do estudo. Por meio de contatos via e-mail, telefone, correio, visitas e reuniões técnicas, quatro empresas iniciaram o processo da pesquisa, despendendo diversos recursos, como tempo, financeiros, humanos dentre outros, e acabaram por não concordar com a realização do estudo de caso.

A empresa escolhida para o estudo de caso foi a Empresa Alfa, organização de base florestal, que fornece carvão vegetal para outra unidade do grupo (Empresa Beta), ambas alocadas no estado de Minas Gerais. A utilização das denominações Alfa e Beta foi um pedido da empresa em estudo. Com escritórios em três cidades no estado (Belo Horizonte, Itamarandiba e Capelinha), a Alfa tem como principal região de atuação, no plantio de eucalipto, o Vale do Jequitinhonha.

Uma entrevista de pesquisa é feita pelo propósito de aumentar o conhecimento (Wengraf, 2001). A entrevista semiestruturada foi a escolhida por partir de certos questionamentos apoiados em teorias e hipóteses que interessam à pesquisa e que, em seguida, oferecem amplo campo de interrogativas, fruto de novas hipóteses que vão surgindo, à medida que se recebem as respostas do informante. Esse tipo de entrevista foi considerado o que oferecia abrangência maior de respostas dos entrevistados e, portanto, mais ampla base de dados, sem perder, no entanto, o direcionamento que a estrutura proporciona (Treviños, 1987 como citado em Buffara, 2003).

Entrevistas internas foram realizadas com 11 empregados da Empresa Alfa dos escritórios de Capelinha, Timóteo e Belo Horizonte que ocupavam cargo de diretoria, gerência ou que estivessem, 
de alguma forma, ligados diretamente à diretoria. A escolha desse grupo, em detrimento dos demais funcionários da empresa, pressupôs que esses profissionais teriam mais aptidão para contribuir com as necessidades do estudo.

As entrevistas externas equivalem aos stakeholders externos. Esses atores foram mencionados durante a pesquisa como parte interessada no negócio e/ou foram indicados por profissionais da empresa. Foram entrevistados: o órgão ambiental A da cidade de Capelinha e o de Minas Novas, voltado para execução de políticas florestais; o órgão ambiental B da cidade de Capelinha, voltado para coordenação, execução e fiscalização de programas de defesa sanitária animal e vegetal; um órgão municipal do setor de agricultura e meio ambiente da cidade de Minas Novas; um órgão municipal do setor de saúde da cidade de Minas Novas; a Associação Comercial de Minas Novas; a ONG A de Minas Novas, voltada para os lavradores e às crianças da área rural; a ONG B que assessora os movimentos populares do Vale do Jequitinhonha; o Parceiro A, voltado para apoiar os pequenos empresários da região; o Cliente $\mathrm{A}$, uma empresa associada à Alfa que compra seu eucalipto para processamento múltiplo; o Fornecedor A, que comercializa máquinas e motores ligados ao negócio da Alfa; o órgão ambiental B da Regional de Teófilo Otoni, também voltado para a coordenação, execução e fiscalização de programas de defesa sanitária animal e vegetal; a Gerência de Suprimentos da Empresa Beta, que realiza a compra de alguns materiais para a Alfa; e a Gerência de Redução da Empresa Beta, que é quem recebe todo o carvão produzido pela Alfa.

Os dados secundários (análise de documentos internos - stakeholders internos e externos - e bibliográficos) consistem num extenso material sobre os assuntos levantados durante as entrevistas para efeito de balizamento na triangulação dos dados, como, por exemplo, o Jornal Florestal, jornal de circulação interna na Empresa; documentos internos dos stakeholders externos, como pautas de reuniões, projetos ainda não realizados, assim como investigação de sites na internet e trabalhos acadêmicos sobre a região do Vale do Jequitinhonha.

Sabendo que os estudos de caso não devem ficar limitados a uma única fonte de evidência, a técnica utilizada para coleta e tratamento dos dados tem como objetivo principal o desenvolvimento de linhas convergentes de investigação, proporcionando conclusões mais convincentes e acuradas sobre um mesmo fenômeno. Dessa forma, tem-se na triangulação dos dados um fundamento lógico para se utilizar várias fontes de evidências (Yin, 2001).

Figura 3: Triangulação dos Dados

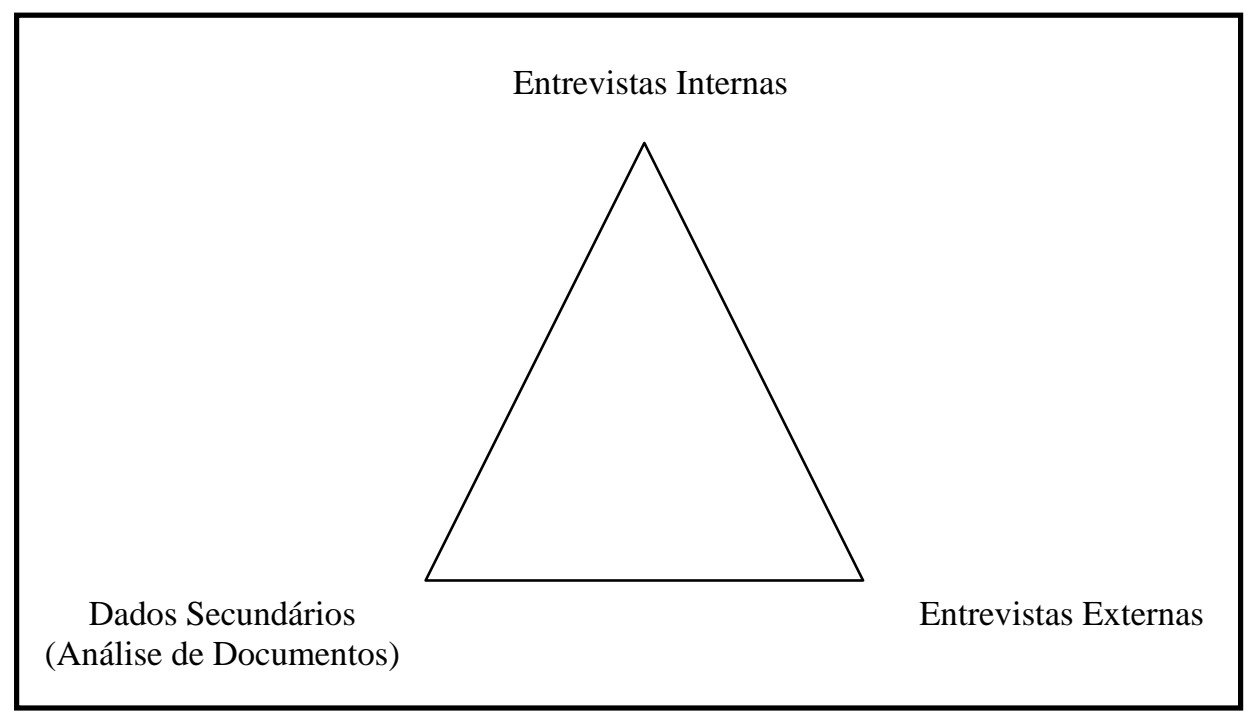

Fonte: adaptado de Yin (2001, p. 121).

A análise de conteúdo é um instrumental metodológico que se pode aplicar em discursos diversos e a todas as formas de comunicação, seja qual for a natureza do seu suporte. O pesquisador deve buscar 
compreender as características, estruturas e/ou modelos que estão por trás dos fragmentos de mensagens tomados em consideração (Godoy, 1995).

Após o término da pesquisa empírica, a etapa seguinte foi a transcrição das entrevistas para posterior avaliação das informações contidas nas gravações. Várias leituras e exame profundo do material coletado permitiram desenvolver a análise e interpretação dos dados.

Para análise dos dados qualitativos foram utilizadas as técnicas de análise de cluster para agrupar diferentes expressões encontradas nas análises dos documentos e nas falas dos entrevistados internos e externos que possuem significado semelhante para efeito da pesquisa (Miles \& Huberman, 1994, tradução nossa).

\section{Resultados dA Pesquisa}

A Tabela 1 e a Figura 4 a seguir apresentam os resultados da análise dos dados das entrevistas, utilizando-se o modelo proposto por Mitchell et al. (1997). Aqui cabe uma consideração com relação ao stakeholder invasores de terra, pois eles não foram entrevistados, e sua classificação se deu de forma apenas indireta, ou seja, conforme os dados coletados pelos stakeholders internos e externos e pela análise dos documentos.

Tabela 1: Classificação dos Stakeholders da Empresa Alfa segundo modelo de Mitchell et al. (1997)

\begin{tabular}{|l|c|c|c|l|}
\hline \multicolumn{1}{|c|}{ STAKEHOLDER } & PODER & LEGITIMIDADE & URGÊNCIA & CLASSIFICAÇÃo \\
\hline Comunidade & & $\mathrm{X}$ & $\mathrm{X}$ & Dependente \\
\hline Sindicato & $\mathrm{X}$ & & $\mathrm{X}$ & Adormecido \\
\hline $\begin{array}{l}\text { Órgãos Ambientais (um de Minas } \\
\text { Novas, um de Teófilo Otoni e dois de } \\
\text { Capelinha) }\end{array}$ & $\mathrm{X}$ & $\mathrm{X}$ & $\mathrm{X}$ & Perigosos \\
\hline Invasores de Terra & $\mathrm{X}$ & $\mathrm{X}$ & Arbitrários \\
\hline $\begin{array}{l}\text { Trabalhadores, Secretaria de Saúde, } \\
\text { Fornecedores }\end{array}$ & $\mathrm{X}$ & $\mathrm{X}$ & Dependente \\
\hline $\begin{array}{l}\text { ONGs (A e B) } \\
\text { Gerências de Suprimentos e de Redução } \\
\text { da Empresa Beta }\end{array}$ & $\mathrm{X}$ & $\mathrm{X}$ & & Dominantes \\
\hline
\end{tabular}

Fonte: adaptado de Mitchell et al. (1997, p. 874) aos resultados da pesquisa 
Figura 4: Stakeholders da Empresa Alfa segundo seus Atributos

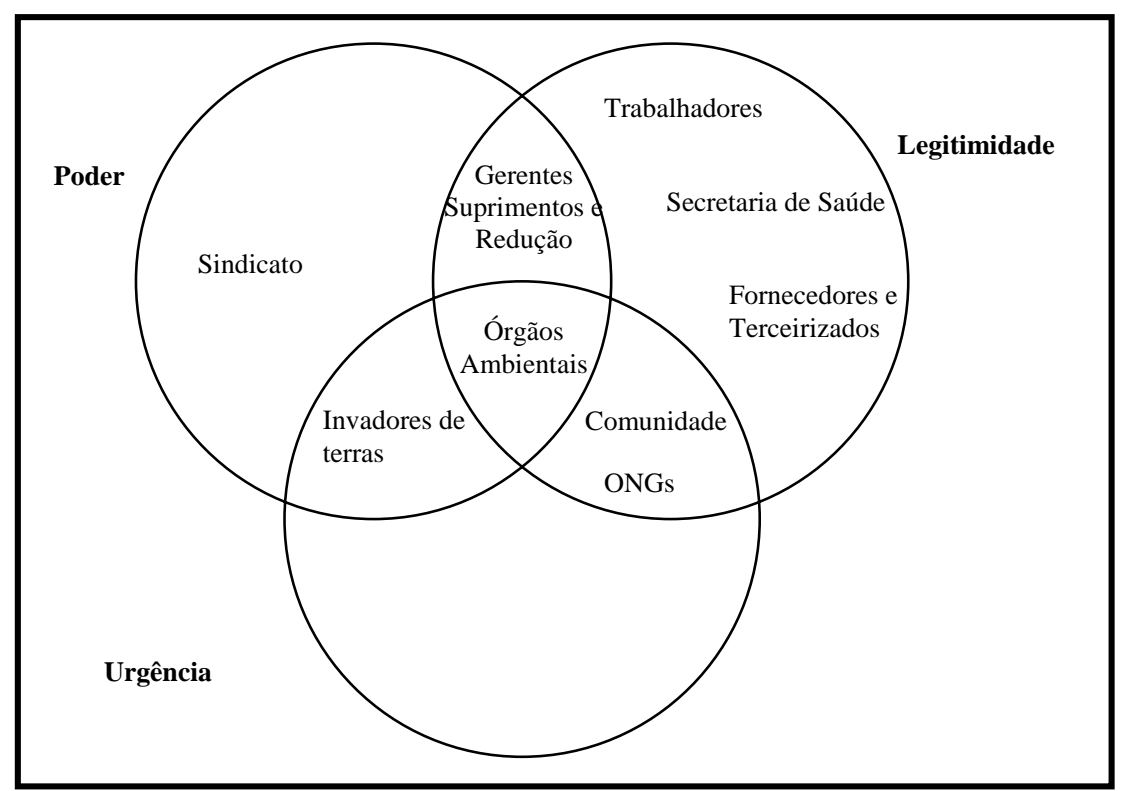

Fonte: adaptado de Mitchell et al. (1997, p. 874) aos resultados da pesquisa.

A seguir, os stakeholders foram analisados com relação aos fatores que afetam seu potencial em ameaçar ou cooperar com a empresa, segundo o modelo de Savage et al. (1991).

A Tabela 2 mostra o resultado da análise.

Tabela 2: Classificação dos Stakeholders da Empresa Alfa segundo Modelo de Savage et al. (1991)

\begin{tabular}{|l|c|c|c|}
\hline \multicolumn{1}{|c|}{ STAKEHOLDER } & POTENCIAL & POTENCIAL EM \\
EM AMEAÇAR & $\begin{array}{c}\text { CLASSIFI- } \\
\text { CAÇÃo }\end{array}$ \\
\hline Associação Comercial de Minas Novas & Alto & Alto & Ambíguo \\
\hline Cliente A & Baixo & Alto & Disposto \\
\hline Fornecedor A & Baixo & Alto & Disposto \\
\hline Gerência de Suprimento e Redução Empresa Beta & Baixo & Alto & Disposto \\
\hline ONG A de Minas Novas & Baixo & Alto & Disposto \\
\hline Órgão Ambiental A de Capelinha & Baixo & Baixo & Disposto \\
\hline Órgão Ambiental B de Capelinha & Baixo & Baixo & Disposto \\
\hline Órgão Ambiental B de Teófilo Otoni & Baixo & Alto & Disposto \\
\hline Parceiro A de Montes Claros & Baixo & Alto & Disposto \\
\hline Secretaria de Saúde de Minas Novas & Baixo & Baixo & Disposto \\
\hline Setor de Agricultura e Meio Ambiente de Minas Novas & Baixo & Baixo & Disposto \\
\hline Trabalhadores & Baixo & Alto & Disposto \\
\hline
\end{tabular}


(conclusão)

Tabela 2: Classificação dos Stakeholders da Empresa Alfa segundo modelo de Savage et al. (1991)

\begin{tabular}{|c|c|c|c|}
\hline STAKEHOLDER & $\begin{array}{c}\text { POTENCIAL } \\
\text { EM AMEAÇAR }\end{array}$ & $\begin{array}{l}\text { POTENCIAL EM } \\
\text { COLABORAR }\end{array}$ & $\begin{array}{l}\text { CLASSIFI- } \\
\text { CAÇÃO }\end{array}$ \\
\hline Órgão Ambiental A de Minas Novas & Alto & Baixo & Indisposto \\
\hline Comunidade & Baixo & Baixo & Marginal \\
\hline Invasores de Terra & Baixo & Baixo & Marginal \\
\hline ONG B de Minas Novas & Baixo & Baixo & Marginal \\
\hline Sindicato & Baixo & Baixo & Marginal \\
\hline
\end{tabular}

Fonte: adaptado de Savage et al. (1991, p. 65) aos resultados da pesquisa.

Dito isso, assim encontram-se dispostos os stakeholders na Figura 5, segundo seu potencial em cooperar e/ou ameaçar a Empresa Alfa.

Figura 5: Diagnóstico dos Stakeholders da Empresa Alfa segundo o Potencial de Cooperar e Ameaçar a Organização Baseado no Modelo de Savage et al. (1991)

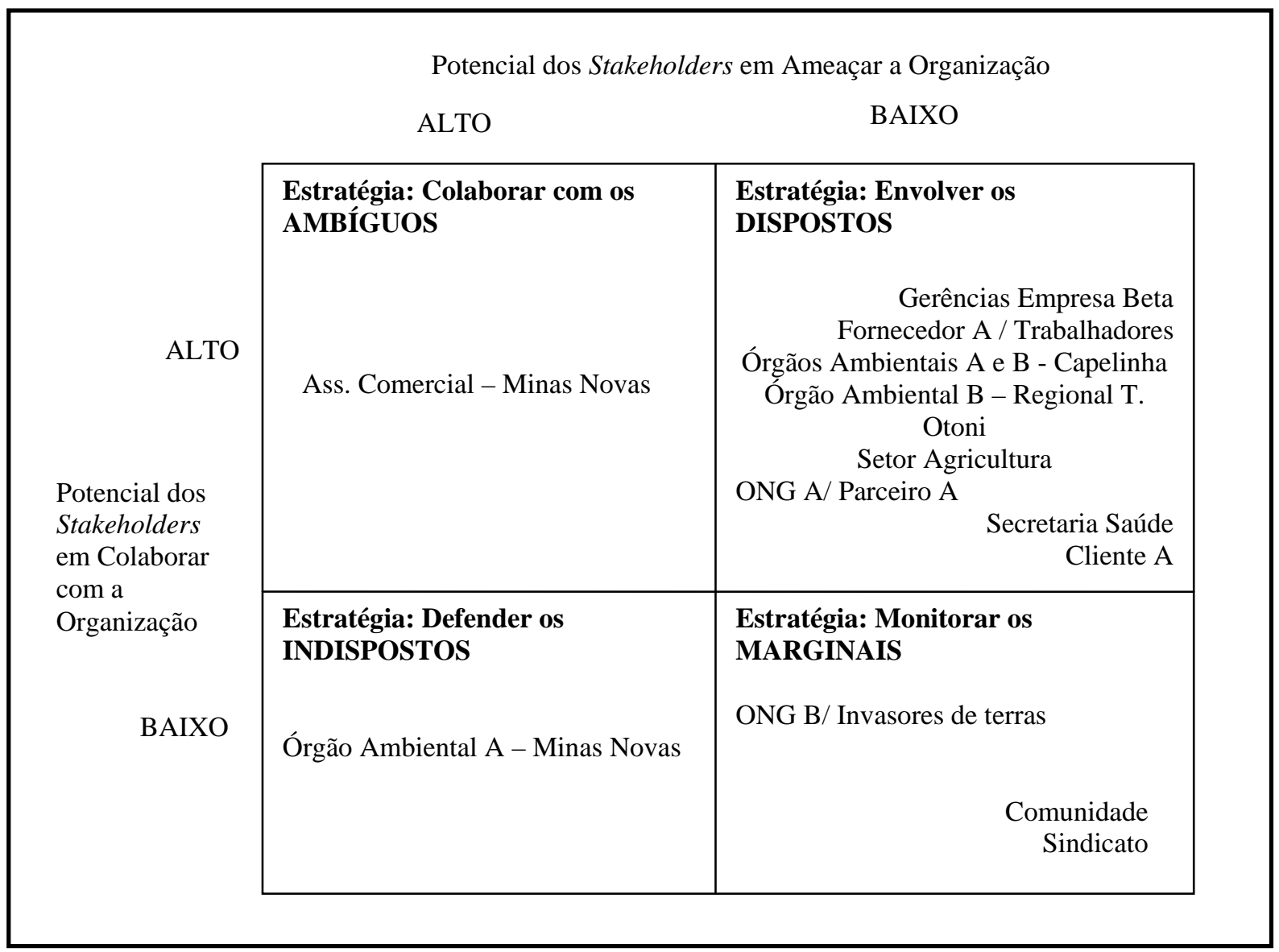

Fonte: adaptado de Savage et al. (1991, p. 65) aos resultados da pesquisa.

Após a análise de dados com a aplicação dos modelos de análise de stakeholder, serão propostas formas de condução do relacionamento da Empresa Alfa e as partes interessadas no seu negócio. 


\section{SUGESTÕES de PolíticAs GeRENCIAS PARA A EMPRESA Alfa}

O ideal seria se existisse uma maneira de administrar todas as partes interessadas, de modo que elas se mostrassem dispostas a cooperar com a empresa e sem apresentar sinais de ameaça (categoria dispostos de stakeholders). Como isso não existe, o gerenciamento de stakeholders é uma forma de balizar os interesses conflitantes e atuar continuamente nessa busca ideal.

Com base no cenário construído anteriormente na Figura 5, agora apresentam-se algumas políticas gerenciais para a Empresa Alfa administrar melhor seus stakeholders.

Figura 6: Simulação de Futuro Diagnóstico dos Stakeholders da Empresa Alfa segundo seu Potencial de Cooperar ou Ameaçar a Organização

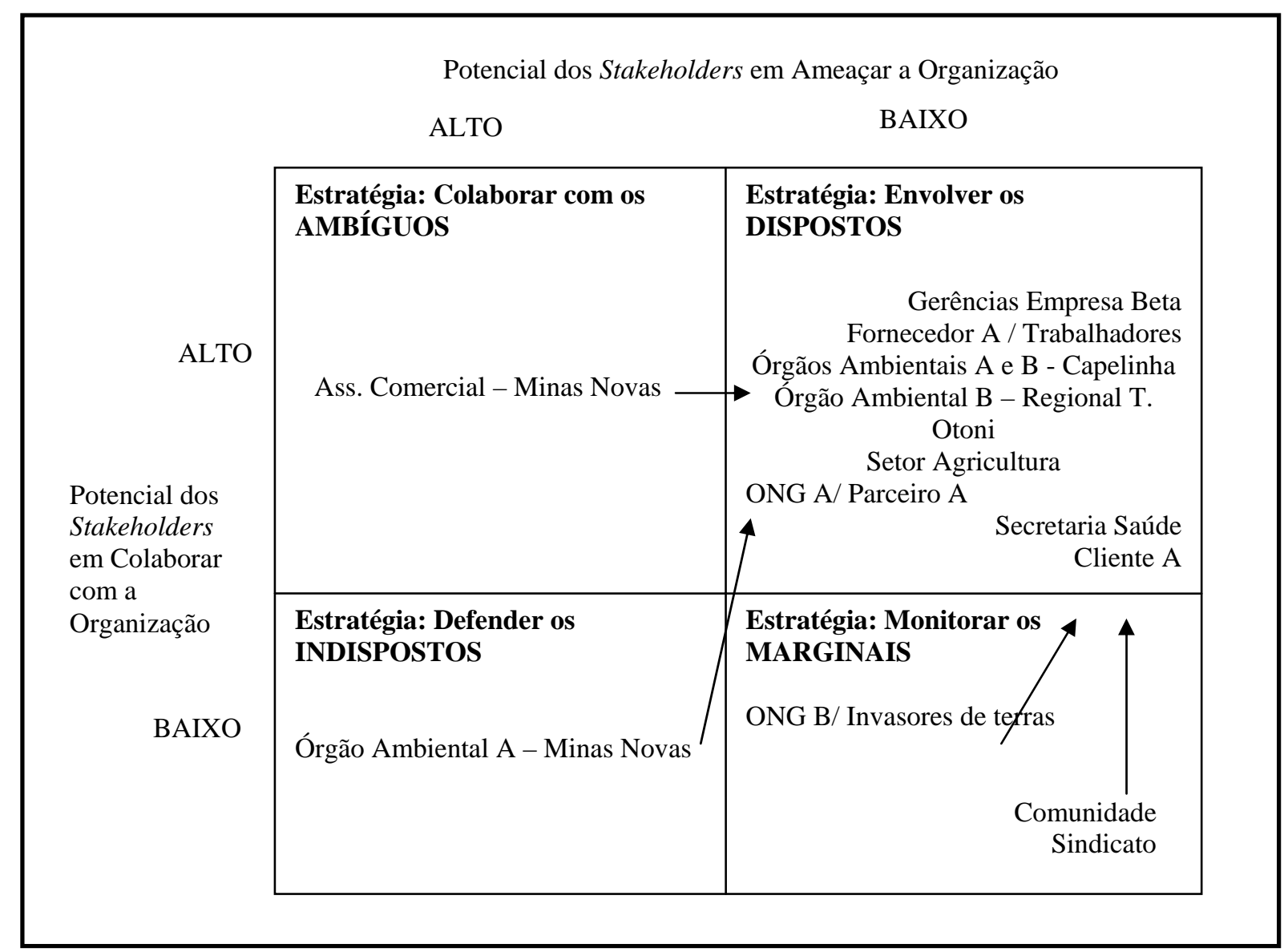

Fonte: adaptado de Savage et al. (1991, p. 65) aos resultados da pesquisa.

Integrando o grupo dos stakeholders dispostos estão as Gerências da Empresa Beta, os Trabalhadores, o Fornecedor A, o Órgão Ambiental B de Capelinha e o Regional de Teófilo Otoni, o Órgão Ambiental A de Capelinha, o Setor de Agricultura e a Secretaria de Saúde de Minas Novas, o Parceiro A, a ONG A e o Cliente A.

Como o potencial em cooperar desse grupo é alto e o de ameaçar é baixo, fica evidente que a construção de parcerias com eles é facilitada por essas questões e deve ser praticada sempre que necessário. É necessário estar atento às sugestões que esses stakeholders fizeram e tentar atendê-los ao máximo, pois é interessante para a empresa que eles continuem nesta posição no gráfico. 
Já o grupo dos marginais configura a ONG B, juntamente com os Invasores de Terra, os Sindicatos e a Comunidade. É necessário monitorar esse grupo, antes de tentar envolvê-los nos propósitos do negócio da Empresa Alfa, pois eles possuem baixo potencial em cooperar com a empresa.

Especial atenção deve ser dada aos Invasores de Terras e à ONG B, pois eles estão quase migrando para o grupo dos indispostos, o que pode demandar esforços maiores das empresa para lidar com eles. Fica claro aqui que os Invasores de Terra, algumas vezes chamados de partes desinteressadas pelos trabalhadores da Empresa Alfa, merecem acompanhamento com atenção.

Com relação à Comunidade, especificamente, que foi um stakeholder citado por 34,29\% dos entrevistados internos como parte interessada no negócio da Empresa Alfa, é necessário que se promovam intensos estudos e ações para fazê-la migrar para o grupo dos dispostos. Para isso, muitas vezes é interessante lançar mão de parcerias com stakeholders que possuem potencial em cooperar maior, como os do grupo dispostos.

Aqui cabe uma reflexão. Como a Comunidade, que foi reconhecida por parte dos entrevistados internos como stakeholder da Empresa Alfa, pode estar configurada no quadrante dos marginais? Se, segundo Freeman (1984), stakeholder é aquele que impacta ou é impactado pela organização, seria mesmo baixo o potencial da comunidade em atrapalhar os planos de ação da Empresa Alfa? E o potencial em agregar mão-de-obra, prestar serviços, dentre outras atividades, seria realmente baixo? Esta pode ser a estratégia da Empresa Alfa, já que o gráfico foi construído segundo as entrevistas dos colaboradores da empresa? Como discutir a Responsabilidade Social numa empresa em que a Comunidade aparece não sendo praticamente considerada parte interessada? Seria este um viés específico desta empresa ou caso a ser estudado mais amplamente em outras organizações?

No grupo dos indispostos ficou o Órgão Ambiental A de Minas Novas e isso se deu pelo fato de ser um órgão fiscalizador ambiental, que não tem o interesse em se coligar com a empresa ou apoiá-la de outra forma. Uma ação com o Órgão Ambiental A de Capelinha, por exemplo, poderia fazê-lo começar a repensar em cooperar com a Empresa Alfa.

No grupo dos ambíguos ficou a Associação Comercial de Minas Novas. O perigo aqui está no fato do alto potencial em ameaçar a Empresa Alfa, e isso significa alianças com outros stakeholders, o que pode atrapalhar a administração de partes interessadas da empresa. É necessário que a empresa se aproxime da Associação, indicando quais são as vantagens de cooperar com ela e fazer com que, aos poucos, esse stakeholder migre para o grupo dos dispostos.

Muitas vezes, no decorrer do estudo, ocorreram evidências que podem indicar a ausência de transparência advinda do desalinho dos discursos, o que pode reduzir a confiabilidade e todos os esforços empresariais em melhorar a imagem da Empresa Alfa perante os stakeholders.

A ausência de uma gestão transparente pode gerar conflitos de relacionamento entre a Empresa Alfa e seus stakeholders. Ao alinhar à sua estratégia ações de transparência, os stakeholders nivelarão seus conceitos sobre a empresa e, em decorrência disto, o diálogo será facilitado, de modo que a gestão de partes interessadas terá vantagens neste processo que consiste em maior aproximação entre as percepções dos stakeholders internos e externos, assim como todo o material que é divulgado ou produzido sobre a Empresa Alfa.

Retomando a pergunta de pesquisa, concluímos o presente estudo, certos de que há o interesse por parte dos stakeholders da Empresa Alfa com relação ao processo de sustentabilidade empresarial e que, de fato, a administração de partes interessadas interfere neste processo. Os modelos aplicados ao estudo permitiram uma visualização atual e futura de como o relacionamento com stakeholders poderá ser moldado. Entretanto cabe à Empresa Alfa acatar ou não as sugestões deste estudo e acompanhar sua eficiência ao longo do tempo. Estudos subseqüentes serão relevantes para analisar como se dará esta interferência e quais serão as reações desses stakeholders de acordo com as estratégias tomadas pela empresa. 
Como a organização é um sistema complexo e dinâmico, estudos posteriores são válidos e necessários para averiguar a implementação das sugestões, assim como o caminho de sustentabilidade que a empresa vem trilhando.

Artigo recebido em 07.07.2008. Aprovado em 11.12.2008.

\section{AGRADECIMENTOS}

Os autores agradecem o apoio financeiro do Conselho Nacional de Desenvolvimento Científico e Tecnológico [CNPq], a todos os revisores deste artigo, e às solidárias e sempre pertinentes sugestões da colega Teresa Cristina Janes Carneiro.

\section{REFERÊNCIAS BIBLIOGRÁFICAS}

Almeida, A. L. C., \& Muniz, R. M. (2005, setembro). A construção da reputação organizacional como recurso estratégico: o papel dos gestores e a percepção dos stakeholders. Anais do Encontro Nacional da Associação Nacional de Pós-Graduação e Pesquisa em Administração, Brasília, DF, Brasil, 29.

Bourne, L., \& Walker, D. H. T. (2005). Visualising and mapping stakeholder influence. Management Decision, 43(5), 649-660.

Buffara, L. C. B. (2003). Desenvolvimento sustentável e responsabilidade social: um estudo de caso no grupo O Boticário. Dissertação de mestrado não-publicada, Universidade Federal de Santa Catarina, Florianópolis, SC, Brasil.

Costa, A. M., \& Carvalho, J. L. F. (2005, setembro). Legitimando papéis ou conciliando interesses? A reprodução discursiva da responsabilidade social empresarial. Anais do Encontro Nacional da Associação Nacional de Pós-Graduação e Pesquisa em Administração, Brasília, DF, Brasil, 29.

Donaire, D. (1999). Gestão ambiental na empresa. São Paulo: Atlas.

Freeman, R. E. (1984). Strategic management: a stakeholder approach. Massachusetts: Pitman.

Godoy, A. S. (1995). Pesquisa qualitativa: tipos fundamentais. Revista de Administração Pública, 35(3), 20-29.

Miles, M. B., \& Huberman, A. M. (1994). Qualitative data analysis: an expanded sourcebook. Thousand Oaks: Sage Publications.

Mitchell, R. K., Agle, B. R., \& Wood, D. J. (1997). Toward a theory of stakeholder identification and salience: defining the principle of the who and what really counts. Academy of Management Review, 22(4), 853-886.

Mostardeiro, M. M., \& Ferreira, G. C. (2005, setembro). Análise das estratégias de responsabilidade social e sua inserção na estratégia corporativa de três empresas do Rio Grande do Sul. Anais do Encontro Nacional da Associação Nacional de Pós-Graduação e Pesquisa em Administração, Brasília, DF, Brasil, 29.

Rowley, T. (1997). Moving beyond dyadic ties: a network theory of stakeholder influences. Academy of Management Review, 22(4), 887-910. 
Savage, G. T., Nix, T. W., Whitehead, C. J., \& Blair, J. D. (1991). Strategies for assessing and managing organizational stakeholders. Academy of Management Executive, 5(2), 61-75.

Tachizawa, T. (2002). Gestão ambiental e responsabilidade social corporativa: estratégias de negócios focadas na realidade brasileira. São Paulo: Atlas.

Tapscott, D., \& Ticoll, D. (2005). A empresa transparente. São Paulo: M. Books do Brasil.

Wengraf, T. (2001). Qualitative research interviewing: biographic narrative and semi-structured method. London: Sage Publications.

Yin, R. K. (1994). Case study research, design and methods (Vol. 5). Thousand Oaks: Sage Publications.

Yin, R. K. (2001). Estudo de caso: planejamento e métodos. São Paulo: Bookman. 